\title{
Resposta inflamatória e deposição de colágeno após implante intramuscular com polimetilmetacrilato em camundongos Balb/c
}

\author{
Inflammatory response and a deposit of collagen after intra muscular implant with \\ Polymethilmethacrylate in Balb/c mice
}

\section{Eduardo Martins Sousa', Eduardo Luiz Costa2, Ediane Batista Silva ${ }^{3}$, João Alves Araújo Filho ${ }^{4}$, Ruy Souza Lino-Junior ${ }^{5}$ \& Ana Paula Junqueira-Kipnis ${ }^{5}$}

\begin{abstract}
RESUMO
O preenchimento de tecidos com partículas tem sido largamente utilizado, entretanto, é necessário estudar suas possíveis reações adversas. Este estudo avaliou a resposta inflamatória e deposição de colágeno após implante intramuscular de polimetilmetacrilato (PMMA) em camundongos BALB/c. Implantou-se 100 il de PMMA na pata direita e, posteriormente, realizou-se a pesagem dos músculos e coletou-se tecido para análise histopatológica e imunohistoquímica. Na morfometria encontrou-se microesferas de 10,9 a $50 \mathrm{~mm}$. Houve diferença na pesagem dos músculos p<0,01. Encontraram-se macrófagos presentes no infiltrado inflamatório, microesferas de PMMA e deposição de colágeno. Na imunohistoquímica, as células apresentaram marcação positiva para CD68. As microesferas de polimetilmetacrilato não induziram a uma resposta inflamatória crônica.
\end{abstract}

Descritores: fagocitose, inflamação, polimetilmetacrilato.

\section{ABSTRACT}

The tissues felling with particles has been widely used, however it is necessary to study possible adverse reactions of these application. This study evaluated the inflammation response of collagen after intramuscular implant of polymethilmethacrylate (PMMA) in Balb/c mice. It was implanted 100 il of PMMA in left hind, later the muscles were weighed with and without implants and tissue was colleted for histopathological and immunohistochemical analysis. In the morphometry found microspheres of 10.9 and $15 \mu \mathrm{m}$. There was a difference in the weight of the muscles $\mathrm{p}<0,01$. The macrophages phagocyting PMMA were found and there was a deposit of collagen in the conjuntive tissue. In the immunohistochemical analysis the cells presented positive marking for CD68. The microspheres of PMMA did not lead to a chronic inflammatory response.

Key words: inflamation, phagocitose, polymethilmethacrylate. 


\section{INTRODUÇÃO}

Nas técnicas modernas de estética, o preenchimento de tecidos com partículas tem sido largamente utilizado, no entanto, faz-se necessário estudar as possíveis reações adversas dessa aplicação.

Em medicina veterinária a utilização de preenchimento de tecido tem sido empregada após remoção ocular e outros implantes que visam corrigir algum defeito, principalmente em animais de estimação ou em raças destinadas a competições $[8,16]$.

Na medicina humana, essas técnicas são utilizadas principalmente na correção da perda de elasticidade da pele $[3,10,22]$. Em implantes com gel biocompatível, utilizado para aumentar o volume de determinadas regiões do corpo, o polimetilmetacrilato (PMMA) é o produto mais procurado $[9,15,16,18]$. O PMMA também é indicado para a correção volumétrica facial e corporal da lipodistrofia gerada pelo uso de antiretrovirais em pacientes portadores do vírus HIV 1/2 [1,2,5,11,12].

As técnicas de preenchimento de tecidos usadas na medicina humana e veterinária devem ser pouco invasivas, com baixa taxa de morbidade, e apresentarem resultados em curto prazo. Atualmente, as técnicas de bioplastia passaram a ser muito bem aceitas, devido à suas vantagens e, principalmente, por esses procedimentos serem realizados no próprio consultório médico [21].

Tendo em vista o desenvolvimento desta nova técnica para correções estéticas, este trabalho teve como objetivo avaliar o tamanho das partículas de PMMA, o aumento do volume muscular, a deposição de colágeno e o processo inflamatório gerado pelo implante.

\section{MATERIAIS E MÉTODOS}

\section{Partículas de Polimetilmetacrilato (PMMA)}

Foram utilizadas partículas de polimetilmetacrilato $\left(\right.$ Newplastic $^{\circledR}$ ) na concentração de $30 \%$ de PMMA com 40mm de diâmetro, para uso intramuscular dissolvido em hidrogel estéril (lote 0701C). Para avaliar o tamanho das partículas de PMMA foram feitos esfregaços e observados em microscopia de luz. As imagens foram digitalizadas e analisadas de acordo com o software image $J(1.37 \mathrm{v}$, Wayne Rasband NIH, USA. http://rsb.info.nih.govv/ij ).

\section{Implante em camundongos}

O estudo foi realizado em camundongos isogênicos $\mathrm{BALB} / \mathrm{c}$ machos com idade variando entre 4 e 8 semanas, criados e mantidos no Biotério do Instituto de Patologia Tropical e Saúde Pública - UFG. Os animais foram manejados de acordo com os critérios do Colégio Brasileiro de Experimentação Animal (COBEA) e anestesiados com solução 1:1 (0,4mg/ $\mathrm{Kg}$ ) de cloridrato de 2 (2-6-xilidino)-5,6-dihidro4h-1,3-tiazina e cloridrato de ketamina. Após imobilização em decúbito ventral foi realizada a tricotomia dos membros posteriores e anti-sepsia com álcool a $70 \%$. Posteriormente, uma incisão na derme com uma agulha $12 \mathrm{G}$ foi realizada para permitir a passagem da microcânula para o implante de 100ml de PMMA $30 \%$ na porção posterior do músculo gastrocnêmico da perna esquerda do camundongo. Como controle, foi usado o músculo gastrocnêmico da perna direita do mesmo animal. Foram analisados os seguintes pontos experimentais: P1: 15 dias, P2: 30 dias, P3: 60 dias, P4: 90 dias e P5: 120 dias com $n=3$ para cada ponto experimental.

\section{Avaliação histopatológica}

Nos tempos experimentais pré-estabelecidos, os animais foram sacrificados por deslocamento cervical e os membros posteriores foram coletados e fixados em álcool 70\%. Os músculos gastrocnêmicos foram dissecados e cortados em fragmentos longitudinais que, por sua vez, foram desidratados em soluções alcoólicas de concentração crescente $(80,90$ e $100 \%$ ), diafanizados em xilol e incluídos em parafina de baixo ponto de fusão. Os blocos foram cortados em fragmentos de $5 \mathrm{~mm}$ de espessura e corados por Hematoxilina-Eosina (H\&E) e Picrosírius (solução aquosa saturada de ácido pícrico adicionada de 0,1\% de vermelho da Síria F3b, Sirius red F3B-Bayer) [14], com contra-coloração pela hematoxilina por 1 minuto. As lâminas foram avaliadas em microscopia de luz. As imagens foram digitalizadas e analisadas de acordo com o software image $J(1.37 \mathrm{v}$, Wayne Rasband NIH, USA. http://rsb.info.nih.govv/ij)

\section{Imunohistoquímica}

Os cortes histológicos de 4 a $5 \mu \mathrm{m}$ foram desparafinizados e incubados por 15 minutos com tampão citrato $\mathrm{pH}$ 6,4, sendo posteriormente lavados com solução salina. A seguir, as amostras foram incubadas por 18 horas à temperatura de $4^{\circ} \mathrm{C}$ ou com anticorpo monoclonal anti-CD68 $\left(\mathrm{DAKO}^{\circledR}\right)$ para macrófagos e anticorpo monoclonal anti-CD3 $\left(\mathrm{DAKO}^{\circledR}\right)$ para linfócitos. Após a lavagem com salina, as amostras foram incubadas com anticorpo secundário anti-IgG total de 


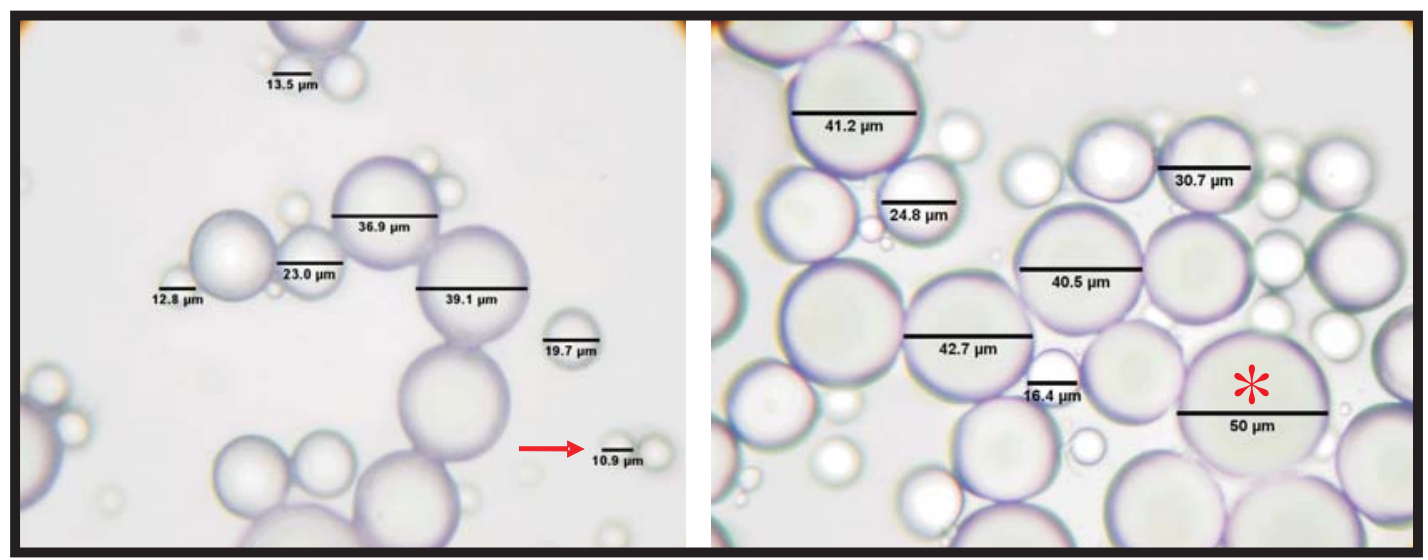

Figura 1. Fotomicrografias do esfregaço de Newplastic ${ }^{\circledR}$ observadas em microscopia de luz, onde foram encontradas partículas com diferentes tamanhos. Partículas de PMMA com diâmetro de 10,9mm (seta) e de $50 \mathrm{~mm}(*)$.

camundongo conjugado com peroxidase por $60 \mathrm{mi}-$ nutos à temperatura ambiente. Para visualização, as amostras foram tratadas com solução diaminobenzidina (DAB) e então contra-coradas com hematoxilina para visualização em microscopia de luz.

\section{Análise estatística}

Para a análise das médias e desvios padrão dos resultados encontrados, foi realizado análise de variância (ANOVA) e os resultados obtidos avaliados em teste " $t$ ". Foram definidos como estatisticamente diferentes resultados com $\mathrm{p}<0,05$.

\section{RESULTADOS}

\section{Avaliação do tamanho das partículas de PMMA}

Com o intuito de verificar a padronização recomendada do tamanho das esferas disponíveis para bioplastia de $40 \mathrm{~mm}$, foi avaliado o tamanho das partículas de PMMA usadas neste trabalho. Foi realizado um esfregaço para observação em microscopia de luz, no qual as imagens foram digitalizadas e analisadas com o programa Image J. A média do tamanho das partículas de PMMA encontrada foi 30,39 $\mathrm{mm} \pm 13,44$ (Figura 1).

\section{Avaliação no aumento do volume muscular após o implante de PMMA}

Para avaliar o aumento do volume muscular após o implante de PMMA, foi realizada a pesagem dos membros posteriores (teste e controle) de cada camundongo nos diferentes pontos experimentais. Observou-se aumento no volume muscular apenas no grupo analisado com 60 dias após o implante de PMMA $(\mathrm{p}=0,01)$ [Tabela 1].
Tabela 1. Comparação do peso em gramas dos membros posteriores, esquerdo e direito, dos camundongos BALB/c, implantados com PMMA e sem implante (controle), respectivamente.

\begin{tabular}{|c|c|c|}
\hline Pontos Experimentais $^{\text {a }}$ & Com PMMA & Sem PMMA \\
\hline $\mathbf{1 5}$ dias & $1,46 \mathrm{~g} \pm 0,04$ & $1,34 \mathrm{~g} \pm 0,06$ \\
\hline $\mathbf{3 0}$ dias & $2,02 \mathrm{~g} \pm 0,13$ & $1,81 \mathrm{~g} \pm 0,13$ \\
\hline $\mathbf{6 0}$ dias* & $1,66 \mathrm{~g} \pm 0,14$ & $1,28 \mathrm{~g} \pm 0,07$ \\
\hline $\mathbf{9 0}$ dias & $1,46 \mathrm{~g} \pm 0,09$ & $1,31 \mathrm{~g} \pm 0,06$ \\
\hline $\mathbf{1 2 0}$ dias & $1,3829 \mathrm{~g} \pm 0,05$ & $1,33 \mathrm{~g} \pm 0,03$ \\
\hline
\end{tabular}

${ }^{a}$ Animais foram inoculados com 100ml de PMMA no músculo gastrocnêmico.

*Aumento do peso do membro posterior estatisticamente significante $\mathrm{p}=0,01$.

Reação inflamatória induzida pelo implante intramuscular de PMMA

Para avaliar a reação inflamatória gerada pelo implante intramuscular de PMMA foram analisados cortes histológicos corados por H\&E, onde se observou um infiltrado inflamatório difuso no sítio de implante do PMMA, áreas de hiperemia, infiltrado de células mononucleares em torno das partículas de PMMA, que aumentaram gradativamente até os 30 dias após o implante (Figura 2B). Não foi observado necrose no tecido adjacente, formação de granulomas e neovascularização. Após este período, o infiltrado de células mono-nucleares diminui gradativamente. $\mathrm{O}$ tamanho das microesferas depositadas no local de implante variava durante o período estudado. No início do implante, 


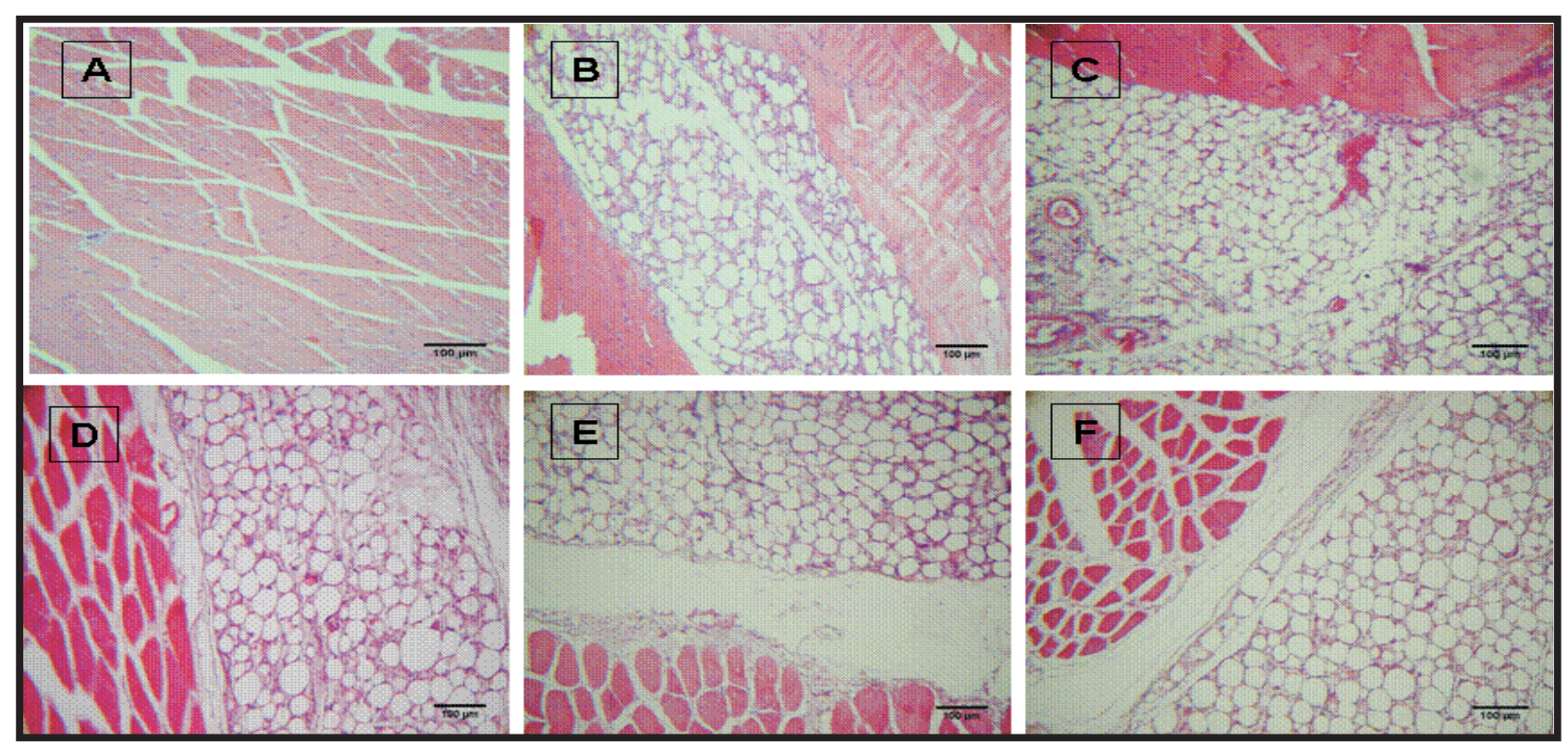

Figura 2. Fotomicrografias do tecido muscular do membro posterior de camundongo BALB/c. A) Membro posterior direito (controle sem implante de PMMA). B-F) membro posterior esquerdo implantado com PMMA, com 15, 30, 60, 90 e 120 dias respectivamente, coradas com HE, observadas em microscopia de luz, escala =100mm.

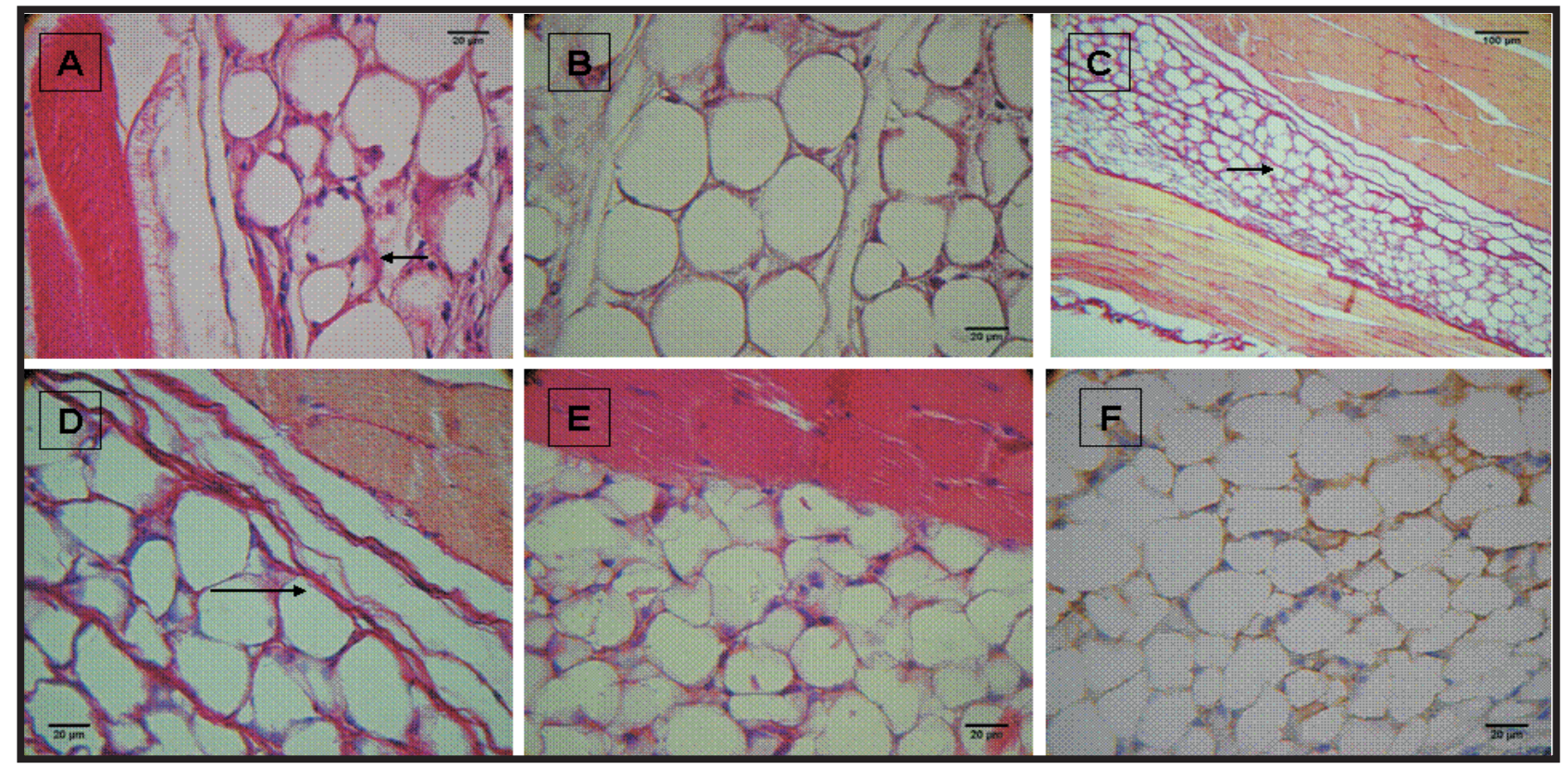

Figura 3. Fotomicrografias do tecido muscular do membro posterior de camundongo BALB/c implantados com PMMA com 60(A) e 120(B) dias respectivamente, coradas com HE, observadas em microscopia de luz, escala = 20mm. (A) Presença de infiltrado de células mononucleares (seta), microesferas de PMMA com tamanhos variados. (B) Predomínio de microesferas maiores de PMMA. Fotomicrografias do tecido muscular do membro posterior de camundongo BALB/c implantados com PMMA com 30 dias após o implante com PMMA, coradas por Picrosírus. Observadas em microscopia de luz, escala $=100 \mathrm{~mm}(\mathrm{C})$, e escala $=20 \mathrm{~mm}(\mathrm{D})$, respectivamente, onde já se observa a deposição de colágeno no tecido adjacente entre a musculatura e o sítio de implante de PMMA (C) e entre as microesferas de PMMA (D). Fotomicrografias do tecido muscular do membro posterior de camundongo BALB/c, após 30 dias implante com PMMA, onde o infiltrado inflamatório apresentava menor quantidade de células. (E) Coradas por H\&E. (F) Coradas por imunohistoquímica. Marcação positiva para CD68 (coloração marrom). Obsevadas em microscopia de luz escala = 20mm. 
em 15, 30 e 60 dias haviam microesferas de tamanhos variados. A partir de 90 dias do implante, somente microesferas maiores que $30 \mathrm{~mm}$ permaneceram no sítio de implante intramuscular (Figura 3B).

\section{Deposição de colágeno}

Para avaliar a deposição de colágeno, as lâminas foram coradas por Picrosírius, onde demonstrou um aumento gradativo na quantidade de colágeno, de acordo com os pontos experimentais tanto no tecido adjacente entre o local de implante de PMMA (Figura 3C), como entre as microesferas de PMMA (Figura 3D), porém, a quantidade de colágeno variava de discreto a moderado.

\section{Avaliação imunohistoquímica para macrófagos}

Para avaliar as células presentes no infiltrado inflamatório, os tecidos musculares implantados com PMMA foram marcados em imunohistoquímica para macrófagos e linfócitos, sendo assim, pode-se confirmar que as células presentes no infiltrado inflamatório eram macrófagos, uma vez que apresentaram marcação positiva para CD68 (Figura 3F) e marcação negativa para CD3. A imunohistoquímica foi realizada com 30 dias após o implante de PMMA, pois o infiltrado inflamatório se apresentava com uma quantidade menor de células.

\section{DISCUSSÃO}

Neste estudo foram usadas microesferas de PMMA, as quais são amplamente empregadas em procedimentos de bioplastia. O tamanho da microesfera foi de aproximadamente $30,39 \mu \mathrm{m}$, estando, portanto, dentro das recomendações feitas por [20], que afirmaram que microesferas com tamanho entre 30 a $50 \mu \mathrm{m}$ escapam da fagocitose e de deslocamentos. Apesar de terem sido observadas partículas com tamanho de $16,85 \mu \mathrm{m}$, [15] afirmaram que mesmo com melhoras significativas na fabricação do PMMA, a partir de 2003, ainda é possível detectar, em média, quase $1 \%$ de microesferas menores do que $20 \mu \mathrm{m}$, as quais podem ser fagocitadas sofrendo migração para outros órgãos, inclusive os órgãos linfóides secundários, segundo observações feitas por [19].

A pequena variação da massa muscular dos membros nos quais foi injetado o PMMA, pode ser explicada pelo fato das análises terem sido feitas no período de quatro meses pois, segundo [5], estudando as reações adversas após preenchimento de tecidos conjuntivos com microesferas de PMMA em humanos, observaram que é necessário um período mínimo de seis meses para observar o resultado final da aplicação. A diminuição do peso do músculo pode, ainda, ser decorrente da migração das partículas menores para outras regiões, embora não tenha sido realizada uma avaliação em outros órgãos do camundongo para confirmar a migração de microesferas. Neste sentido, [24] avaliaram a importância do tamanho e composição química de biomateriais empregados para preenchimento de tecidos e sua distribuição pelos diversos tecidos, injetando partículas de PMMA no peritônio de camundongos com tamanho entre 1,2, 5,2 e $12,5 \mu \mathrm{m}$ de diâmetro. Os autores observaram que a intensa fagocitose das partículas pequenas e médias ocorreu no primeiro dia pós-injeção e foram diminuindo gradativamente até o sétimo dia pós-injeção. As partículas de $12,5 \mu \mathrm{m}$ não foram englobadas pelos macrófagos peritoneais. Perceberam também que estes camundongos apresentavam intensa deposição de partículas na polpa vermelha do baço. Esses achados podem explicar a pouca variação da massa muscular, após a aplicação de PMMA nos camundongos deste estudo, pois com a presença de microesferas com tamanho abaixo do preconizado, pode ter ocorrido a migração dessas esferas e, portanto, diminuído o peso no músculo no qual foi injetado o biomaterial.

A avaliação da biocompatibilidade, realizada pela histopatologia, apontou que as microesferas menores do que $30 \mathrm{~mm}$ estavam circundadas por células mononucleares em todos os pontos experimentais. Além disso, no local de implante de PMMA, foi observado um infiltrado inflamatório difuso e áreas de hiperemia. Entretanto, não foram encontradas áreas de necrose, neovascularização e células gigantes de corpo estranho, alterações sugestivas de uma resposta inflamatória. [14] estudaram a formação de granuloma por corpo estranho ao Artecoll em uma mulher com aproximadamente 50 anos de idade, que fora submetida ao implante dessa substância na região do pescoço. Quatro anos após o implante, a paciente apresentou granuloma ao longo do sítio da aplicação do Artecoll. Essas alterações foram responsáveis pela condenação do uso desse produto pelos autores, em locais onde há movimentação no tecido. Estudando reações adversas causadas por substâncias injetáveis para preenchimento permanente de tecido conjuntivo em humanos, encontraram granulócitos polimorfonucleares, linfócitos e grande 
quantidade de bactérias, incluindo microbactérias atípicas, o que causaria uma resposta inflamatória aguda acentuada, culminando com a formação de granulomas, eritrema, edema, podendo levar à necrose [7]. Avaliando fagocitose de nanopartículas, como PMMA, por macrófagos de pessoas soropositivas para HIV 1/2, evidenciou que células infectadas por HIV 1/ 2 tem uma maior susceptibilidade para englobar nanopartículas [23]. Essas reações adversas estão estritamente relacionadas com a assepsia durante o procedimento de implante das substâncias de preenchimento de tecidos [7].

Este estudo apresenta caráter inovador quanto ao uso da técnica de imunohistoquímica para caracterizar as células presentes no infiltrado inflamatório, pois não foram encontrados relatos na literatura consultada, utilizando essa técnica para tal finalidade. $\mathrm{O}$ infiltrado celular apresentou marcação positiva para e CD68, conforme demonstrado na Figura 5b, o que confirma a presença dos macrófagos e exclui a participação de linfócitos nesse processo, uma vez que a marcação para CD3 foi negativa (dados não mostrados). Esses achados estão de acordo com [20], cujo estudo observou que células U-397 (linhagem celular semelhante a macrófagos humanos), células de Langerhans e queratinócitos, podem fagocitar partículas de PMMA menores do que $20 \mathrm{~mm}$ causando uma reação inflamatória aguda. [25] avaliaram processo inflamatório em camundongos BALB/c, inoculando partículas de diferentes tamanhos no joelho e observaram que microesferas de $0,5,2,0$ e $75 \mathrm{~mm}$ são capazes de induzir uma resposta inflamatória, porém, as partículas menores provocam resposta inflamatória mais acentuada do que as de maior tamanho.

A deposição de colágeno entre as microesferas e no tecido adjacente ao local de inoculação de PMMA, aumentou gradativamente no decorrer do experimento. As partículas de PMMA, suspensas em colágeno bovino, são encapsuladas por colágeno imediatamente após o implante, devido às características físicas das microesferas, sendo que, em média, após três meses de implante o colágeno é substituído pelo próprio tecido conjuntivo [4]. Avaliaram o ArteFill suspensão de $20 \%$ de microesferas de PMMA com 30 a $42 \mathrm{~mm}$ de diâmetro em $80 \%$ de colágeno bovino e observaram que, a partir de 1 a 2 meses ocorre a diminuição do colágeno, sendo que essa perda é compensada pelo surgimento de fibroplasia, embora não seja possível observar em menos de seis meses o resultado final da deposição de colágeno [5].

\section{CONCLUSÃO}

Diante destes fatos, conclui-se que o implante intramuscular com PMMA promove deposição de colágeno e não induz uma inflamação crônica, apresentando biocompatibilidade. Os implantes apresentavam infiltrados celulares constituídos de macrófagos. Entretanto, devido à presença de microesferas com tamanho abaixo do preconizado, não houve estabilidade das mesmas no local de implante.

\section{REFERÊNCIAS}

1 Acurcio F.A. \& Guimarães M.D. 1998. Use of health services and progression of AIDS in persons with HIV infection in Belo Horizonte (Minas Gerais), Brazil. Revista Panam en Salud Publica. 4: 331-340.

2 Acurcio F.A., Cesar C.C. \& Guimaraes M.D. 1998. Health care utilization and survival among patients with AIDS in Belo Horizonte, Minas Gerais, Brazil. Cadernos de Saude Publica. 14: 811-820.

3 Aizen E.G.A. 2001. Smoking effect on skin wrinkling in the aged population. International Journal of Dermatology. 40: 431-433.

4 Alcalay J., Alkalay R., Gat A. \& Yorav S. 2003. Late-onset granulomatous reaction to Artecoll. Dermatology Surgical. 29: 859-862.

5 Carruthers A. \& Carruthers J.D. 2005. Polymethylmethacrylate microspheres/collagen as a tissue augmenting agent: personal experience over 5 years. Dermatology Surgical. 31: 1561-1564.

6 Carruthers J.D. \& Carruthers A. 2005. Facial sculpting and tissue augmentation. Dermatology Surgical. 31: 16041612.

7 Christensen L., Breiting V., Janssen M., Vuust J. \& Hogdall E. 2005. Adverse reactions to injectable soft tissue permanent fillers. Aesthetic Plastic Surgical. 29: 34-48.

8 Hamor R.E., Whitley R.D., Mclaughin S.A. \& Lindley D.M. 1994. Intraocular silicone prostheses in dogs: a review of the literature and 50 new cases. Journal of the American Animal Hospital Association. 30:66-69. 
9 Haneke E. 2004. Polymethyl methacrylate microspheres in collagen. Semin Cutan Medical Surgery. 23: $227-232$.

10 Hashizume H. 2004. Skin aging and dry skin. Journal of Dermatology. 31: 603-609.

11 Jones D. 2005. Approaches to treatment of HIV facial lipoatrophy. Skin Therapy Letter. 10: 5-7

12 Jones D. 2005. HIV facial lipoatrophy: causes and treatment options. Dermatology Surgical. 31:1519-1529.

13 Junqueira L.C., Bignolas G. \& Brentani R.R. 1979. Picrosirius staining plus polarization microscopy, a specific method for collagen detection in tissue sections. Histochemistry Journal. 11: 447-455.

14 Kim K.J., Lee H.W., Lee M.W., Choi J.H., Moon K.C. \& Koh J.K. Artecoll granuloma: a rare adverse reaction induced by microimplant in the treatment of neck wrinkles. Dermatology Surgical. 30: 545-547.

15 Krauss M.C. 1999. Recent advances in soft tissue augmentation. Seminary Cutan Medical Surgery. 18: 119-128.

16 Lemperle G., Morhenn V. \& Charrier U. 2003. Human histology and persistence of various injectable filler substances for soft tissue augmentation. Aesthetic Plasict Surgery. 27: 354-366.

17 Lemperle G., Morhenn V.B., Pestonjamasp V. \& Gallo R.L. 2004. Migration studies and histology of injectable microspheres of different sizes in mice. Plast Reconstruction Surgery. 113: 1380-1390.

18 Lemperle G., Romano J.J. \& Busso M. 2003. Soft tissue augmentation with artecoll: 10-year history, indications, techniques, and complications. Dermatology Surgical. 29: 573-587.

19 Mclaughlin S.A. 1990. Evisceration and implantation of intraescleral prosthesis. In: Bojrab M.J., Birchard S.J. \& Tomlinson J.L. (Eds). Current techniques in small animal surgery. 3rd edn. Philadelphia : Lea \& Febiger, pp.117-119.

20 Morhenn V.B., Lemperle G. \& Gallo R.L. 2002. Phagocytosis of different particulate dermal filler substances by human macrophages and skin cells. Dermatology Surgical. 28: 484- 490.

21 Narins R.S., Brandt F., Leyden J., Lorenc Z.P., Rubin M. \& Smith S. 2003. A randomized, double-blind, multicenter comparison of the efficacy and tolerability of Restylane versus Zyplast for the correction of nasolabial folds. Dermatology Surgical. 29: 588-595.

22 Poveda R.B., Murillo J. \& Jimenez Y. 2005. Granulomatous facial reaction to injected cosmetic fillers - a presentation of five cases. Medical Oral and Patology Oral Cirurgy Bucal. 11: 1-5.

23 Schäfer V., von Briesen H., Andreesen R., Steffan A.M., Royer C., Tröster S. \& Kreuter J. 1992. Phagocytosis of nanoparticles by human immunodeficiency virus (HIV)-infected macrophages: a possibility for antiviral drug targeting. Pharmaceutical Research. 9: 541-546.

24 Tomazic-Jezic V.J., Merritt K. \& Umbreit T.H. 2001. Significance of the type and the size of biomaterial particles on phagocytosis and tissue distribution. Journal of Biomedical Mater Research. 55: 523-529.

25 Zysk S.P., Schimitt-Sody G.H., Hansson M., Messmer V. \& Veihelmann A. 2005. Particles of all sizes provoke inflammatory responses in vivo. Clinical Orthopedical. 433: 258-264.

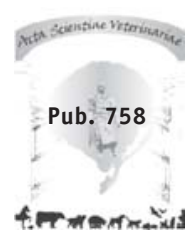


